\title{
Understanding student satisfaction and dissatisfaction: An interpretive study in the UK Higher Education Context
}

This article represents a cross-sectional study of undergraduate students across two

North West University Business Schools in the UK. A purposefully designed questionnaire was collected from 350 students. The student experience was described in the form of hand written narratives by first and final year students and had been identified by the respondents themselves as being satisfying or dissatisfying with the areas of teaching and learning and the supporting service environment. The study also assessed whether their experiences were likely to influence their loyalty behaviours with respect to remaining on their chosen course of study; recommending the university; and continuing at a higher level of study. The data was captured and analysed using the qualitative critical incident technique to capture the voice of the student and identified the critical determinants of quality within Higher Education, i.e. those areas that would influence loyalty behaviour, as being Access; Attentiveness; Availability; and Communication. A number of new determinants of quality have been identified out of the research by three independent judges, namely motivation, reward, social inclusion, usefulness, value for money and fellow student behaviour.

Keywords: Service Quality; Determinants; Critical Incident Technique; Students; Higher Education. 


\section{Introduction}

Student satisfaction (and dissatisfaction) as reported annually in the National Student Satisfaction survey, is one of the many criteria that contribute to universities' league table positions in the United Kingdom (UK). The National Student Survey is a nationwide initiative, which since 2005, has surveyed all final year students studying in publicly funded Higher Education Institutions in England, Wales, Northern Ireland, and the majority of Higher Education Institutions in Scotland. According to the Unistats website ${ }^{1}$, which is owned by the Higher Education Funding Council for England on behalf of all the Higher Education Funding Councils in the UK, the survey yielded a response rate of $62 \%$ for the Business Studies subject area in the 2010-11 academic session. The emphasis on what contributes to a satisfactory or dissatisfactory student experience is set within the context of the creation of a market for university services. Successive UK Governments have subjected Higher Education to severe scrutiny with regards to the cost and quality of their service provision. In particular the quality of the student experience has been positioned high on the national agenda for some time. However, from September 2012, Higher Education institutions are able to set fees for those opting to study in England, Wales and Northern Ireland, up to a maximum of $£ 9,000$ per student for each academic year of undergraduate study.

The two case study universities discussed in this article charge $£ 9000$ and $£ 8000$ for their Business courses. The rises and variation in costs across the country is keeping the issue of value for money very much at the forefront of any selection decision made by prospective students.

\footnotetext{
${ }^{1}$ http://unistats.direct.gov.uk/downloadSpreadsheet.doc
} 
The National Student Survey, originally piloted in 2004, has continued to seek the views of students on a number of aspects of teaching, assessment and on the level of support provided by universities. Results that are made publicly available via a number of websites, including the National Student Survey 2012 aim to ensure prospective students and other stakeholders are given enough information to help choose a university. The National Student Survey results is only one criterion that contributes to league tables for ranking universities and is reported in the national media (Dean 2011). However, the survey has clearly become important in the decision making process for rankings.

\section{Focus of Article}

The use of league tables in the university selection process has forced student opinion and the drivers of satisfaction and/or dissatisfaction for this particular Higher Education stakeholder to the top of universities' agenda. Dean (2011) reported that student satisfaction ratings have been both continuously and increasingly poor and therefore potentially damaging in terms of the recruitment and retention of staff and students. Conversely the UK Government's White Paper (Department for Business, Innovation and Skills, 2011) reported that most students were satisfied with their learning experience and the quality of teaching. Regardless of whether satisfaction is high or low, it remains an issue that is often discussed by experienced and less experienced practitioners.

A conceptual model introduced by Douglas et al (2008) and its application within the Higher Education environment highlighted the critical drivers of satisfaction and dissatisfaction for Higher Education students using the critical incident technique. This encouraged the retelling in narrative form of specific good and bad experiences by students. It was clear, from this research, that the written narratives provided a rich source of data to help a University Faculty understand what drives satisfaction and dissatisfaction for their 
students and was compared with the traditional method of gathering student feedback using mean scores of perceptions or attitudes provided by students for specific areas of teaching and learning.

The main aim of this article is to further explore the conceptual model of Higher Education and the utilisation of critical incident technique for listening to the voice of the student. This will be achieved by using critical incident technique to survey a larger sample of undergraduate business students from two universities, in order to identify those service quality determinants that drive satisfaction, dissatisfaction (or both) and lead to a change in loyalty intentions, such as recommending the university and continuing with their programme of study at their university. Examples of the rich data provided by student respondents are included and will aid the understanding of what satisfies and dissatisfies students. It is proposed that these narratives will help in the process of diagnosing strengths and weaknesses in Higher Education Institution' service provision.

\section{Literature Review}

\section{Higher Education in the UK}

The UK is experiencing in the 21st Century what the United States of America (USA) experienced during the latter part of the 20th Century, that is, the introduction of fees for students of Higher Education. In the USA fees have risen above and beyond the rate of inflation during that time (Eckel and King 2004) with continuing rises in fees and reductions in government support (Eckel 2008). According to federal government statistics in the USA, tuition fees at public universities rose by $32 \%$ by the end of 2009 (Baker 2010). The emphasis is on increasing choice for students in the belief that competition will lead to increased quality and efficiency. 


\section{Quality in Education}

In the 1990s the quality focus shifted to include service businesses as well as manufacturing (Bitner et al 1994) both within the USA and in the UK and in the Higher Education sector in the UK this focus took the form of quality assurance systems that placed an emphasis on the student experience (HEFCE, 2012). In any service organisation, the evidence of service quality is provided during the 'moment of truth' when the customer interacts with the organisation (Carlzon 1987) and this concept still holds today (Carlzon 2006; Fitzsimmons and Fitzsimmons 2004). Customer satisfaction is often influenced by the quality of interpersonal interaction between the customer and the staff member; the quality of which can be affected by the customer's own (mis)behaviour (Bitner et al 1994), as well as by the servicescape itself (Brūggen et al 2011); The servicescape being the physical environment of the supporting services. Therefore, because of the heterogeneity of services and the extent of customer participation varies so too does the nature of the experience (Fitzsimmons and Fitzsimmons 2004). Carlzon (2006) in an interview about managing businesses proposed that within customer relationship management it was this emotional interaction between front line staff and their customers that is the most important issue in building loyalty. Huda and Akhtar (2010) discussed the concept of a 'flawless performance'. Lost customers and negative word of mouth, Bitner et al (1994) found can result from not providing a flawless performance. However, they admitted that it was not always clear how to achieve defect-free performance. Within services, a defect manifests through, inter alia, poor customer satisfaction ratings (Biolos 2002). Biolos (2002) argued that whilst it was relatively easy to tabulate satisfaction responses, it was less easy to 'get a feel' for the highly variable standards that customers use and to have a full understanding of the actual cause of their 
dissatisfaction. Biolos (2002) recommended that services should use a more flexible measurement system and that they should then relentlessly probe the root causes of any dissatisfaction.

\section{Student Feedback and Student Satisfaction}

Herzberg et al (1967) introduced the concept of motivating and hygiene factors (the two-factor theory) which they said influenced job satisfaction and performance. This idea has been related to student satisfaction and dissatisfaction with 'satisfiers' being labelled as motivators and 'dissatisfiers' labelled as 'hygiene factors' (DeShields et al 2005). Herzberg et al (1967) found that not all motivators (satisfiers) were the obverse of the hygiene factors (dissatisfiers) that is, fixing the hygiene factors will not necessarily lead to satisfaction, just to no dissatisfaction. Johnston (1995) also found in a survey of bank customers on their satisfaction that service quality dimensions could be satisfiers or dissatisfiers or both.

\section{Determinants of Quality in Higher Education}

There has been considerable research into identifying dimensions of service quality in Higher Education, with various authors arriving at different lists of antecedents of quality. For example, DeShields et al (2005) used 20 variables in their research into what satisfies American undergraduate business students. LeBlanc and Nguyen (1997) identified 7 dimensions, whereas, Zineldan et al (2011) identified five areas. Athiyaman (1997) identified several areas that should be explored to assess the level of satisfaction from students. The common variables were access and responsiveness. However, there are few studies that made use of the Critical Incident Technique to gauge what is important to students in Higher Education in the teaching and learning and support services contexts. Moreover, the tendency in Higher Education seems to 
be to utilise quantitative measuring techniques to seek views from students on their satisfaction levels. Douglas et al (2008) used CIT to survey undergraduate students on their experiences 'within and beyond the classroom'. They concluded that the critical areas of quality from a student viewpoint were Responsiveness, Communication and Access. They proposed that the neutral areas, i.e. those areas that cause neither satisfaction nor dissatisfaction were reliability; flexibility; aesthetics; comfort; competence; courtesy; credibility; integrity; understanding the customer; security; commitment; functionality and virtual resources. Whilst functionality; socialising; motivation and friendliness were satisfying factors but management; team work; attitude; communication and tangibles were dissatisfiers. They developed a conceptual model of student satisfaction with their higher education experience. These differences in what constitutes service quality within Higher Education may be due to cultural differences. However, it is not clear from the literature why there is such variation.

The UK National Student Survey questionnaire includes 23 statements that ask the respondents to agree or disagree on a 5-point Likert scale (Definitely Agree; Mostly Agree; Neither Agree or Disagree; Mostly Disagree; Definitely Disagree). An example of one of the statements within the teaching section is 'Staff are good at explaining things.' The areas covered were: Teaching; Assessment and Feedback; Academic Support; Organisation and Management; Learning Resources; Personal Development; Overall Satisfaction and Students' Union (Association or Guild). The National Student Survey questionnaire also has a free comment section which enables the respondents to describe a positive experience and a negative experience. 


\section{Critical Incident Technique}

Critical incident technique has been widely used in many service (and other) contexts to measure satisfaction and/or dissatisfaction and to explore their causes, for example services for airlines and restaurants (Bitner et al 1990); for banking (Johnston 1995) for hotels (Edvardsson and Strandvik, 2000); for Healthcare (Kemppainen, 2000) and for wine retailers (Lockshin and McDougall 1998). Very few changes had been made to the original technique made popular by Flanagan (1954) and critical incident technique is still regarded by scholars as both valid and reliable, providing that a number of conditions are met (Gremler 2004). These conditions include that there should be more than one judge to conduct the analysis.

Studies have shown that the qualitative nature of the data results in a 'richness' of information. Johnston (1995) described the 'richness' of this critical incident technique data as being those anecdotes that described a personal experience with the service in question in considerable detail. His research into service quality within banking yielded an anecdote (narrative) with a word length average of just over 30 words, although some had exceeded 100 words. He also found that there were more positive stories from the banks' customers than negative ones. Moreover, some of the negative stories had been derived from a remembered incident from over a decade previously. However, what was significant was that although responses may have been small, the customer loyalty intentions were important to the organisations in terms of retaining and capturing customers and therefore were regarded as significant.

CIT can clearly be used to investigate sources of satisfaction and/or dissatisfaction with service encounters (Gremler, 2004), although it is recognised that there are various constraints, such as remembered incidents which may have been misremembered (Johnston 1995), particularly given that the technique involves asking 
respondents to recall and describe a story about something they have experienced. However, it is regarded as a technique that provides a way in which an organisation can identify how the service affects its various stakeholders, highlight good practice and identify any failures. Given the wide use of satisfaction surveys in the education sector worldwide (Nair et al 2011) and their diagnostic use, it would seem reasonable to suggest that a technique that will provide meaningful data for teaching staff should be employed. Lockshin and McDougall (1988) found that organisations could anticipate potential difficulties and inform their customers by using CIT to anticipate and respond to customer needs. Edvardsson and Roos (2001) demonstrated that it was a tool for managing services and according to Johnston (1995) identifying quality determinants is essential to enable the service delivery to be improved. This is essential in an era where there has been a rapid growth of institutions offering Higher Education and where superior quality may give competitive advantage (Lizuka 2012). Finding out what quality means to the group of stakeholders paying for and receiving the service that is Higher Education can be achieved by critical incident technique.

Critical incident technique facilitates this by providing a mechanism for an individual's perceptions to be expressed in their own words. Content analysis is then undertaken, usually by three independent judges, in order to classify the narratives into relevant themes (variables). This qualitative procedure was compared with the traditional quantitative survey method more commonly adopted within Higher Education institutions by Douglas et al (2009). They found that using critical incident technique complemented existing methods well, particularly when there was a desire by a university faculty to see a more rounded view of the student experience. In the Higher Education context the student experience involves service encounters within the learning and teaching environs, as well as within its supporting environment. 


\section{Methodology}

Making sense of qualitative data is both difficult and time-consuming (Johnson and Christensen 2004). Within business and management research the question of positivism versus phenomenology is important in terms of what philosophy is at the heart of the research (Saunders et al 2009). The phenomenologist believes that the area of business and management is so complex that the researcher should understand the reality behind any given situation (Saunders et al 2009). In order to get a feel for a situation, an inductive approach is required to help build the theory and make sense of the data and the reasons behind behaviours. Data analysis can involve a number of techniques, including Interim Analysis, which involves the researcher alternating between data collection and analysis. Johnson and Christensen (2004) describe this as a discursive process, which occurs until the researcher understands enough about the topic. This can take place over an extended period of time and involve different data collection points. A deeper understanding of the subject matter can then be developed.

The approach for this research was to draw from both qualitative and quantitative data (Creswell, 2009, Cherryholmes, 1992). Guba \& Lincoln, (1994) have identified the postpostivist paradigm as supporting both qualitative and quantitative research. The postpositivist paradigm they propose (ibid.) has an ontology that is one of critical realism, an epistemology that is one of modified objectivist and a methodology that is one of modified experimental and were applied for this research (p.110)

The use of a mix of quantitative and qualitative techniques in the collection and analysis of data had a number of data collection points. An investigation of the 
specific phenomenon in its natural setting was undertaken, that is, within the Higher Education environs. Saunders and Lewis (2012) suggest that people are social actors playing a part on the stage of social life and that people place their own interpretation on the social roles they play. It is also recognized that a researcher's own values also play a role in the definition of what is appropriate (Saunders and Lewis 2012).

Both inductive and deductive reasoning were applied to this investigation. Inductive to explore the phenomenon of student satisfaction across two Universities and across two cohort years, first and final year students, and deductive theories, which used three researchers, as judges, to code student responses against service quality determinants developed by Parasuraman et al (1985) and Johnston (1995), in order to base the research upon. The social world of the students was understood, as recommended by Saunders and Lewis (2012) but through using Critical Incident Technique it was intended to deepen this understanding further. The resultant ontological approach was subjective, however the issue of bias was mitigated by the use of more than one independent judge being involved in the content analysis stage. This provided for investigator triangulation, a strategy using more than one field researcher to collect and analyse the data relevant to a specific research object, (Downward and Mearman 2002). Critical Incident Technique is a qualitative method that facilitates an interpretive approach in the coding of the data. It is not as restricted as the more traditional survey method, which would be limited by the number and type of questions asked (Saunders et al 2009). Once data is themed and coded it is quantified, which in turn facilitates quantitative analysis. To assess reliability, different researchers were used to evaluate whether their observations were similar. This process is associated with an inductive approach (Saunders et al 2009). In order to avoid the threat of subject bias, care was taken over the design of 
the questionnaire particularly that it gave an assurance of anonymity to respondents. As Downward and Mearman (2004) note, there are two main arguments put forward to justify triangulation. The first, put in an early explicit form by Webb et al (1966), is that triangulation increases the 'persuasiveness' of evidence. Many early studies, however, tended to emphasise concerns to enhance the empirical reliability of quantitative measures through triangulation (Campbell and Fiske 1959). Currently, however, the emphasis is more general and shows concerns for enhancing the 'validity' of insights, or for adding 'completeness' to accounts (Shih, 1998). Thus, triangulation elaborates understanding (Jick 1979) or confirms the accuracy of data (Denzin 1989). More explicitly, Danermark et al (2002, p. 153) note the uses of quantitative analysis to 'test' the validity of qualitative insights, or to use qualitative work as preparation for quantitative work, and to elucidate a phenomenon in as much detail as possible

\section{Methods}

The focus of this study was aimed at capturing the voice of the student in order to identify what they deemed was critical to the quality of their student experience. This involved asking individual students to focus on those service encounters that had been particularly satisfying or dissatisfying from their point of view. The students also indicated whether the experience might lead to a change in their future loyalty behaviours and intentions. The objective was to explore how many events could be themed within the existing determinants of service quality introduced by Johnston (1995); Parasuraman et al (1995) and Douglas et al (2008). This exploration and identification of variables took place via a process of iterative readings of the written narratives produced. 
Liamputtong (2009) provides guidance on coding qualitative data, which cited Charmaz (2006) 'on vivo' codes that help to preserve the respondent's literal meaning of their perceptions, for example, If the student mentioned 'access' then the coding assigned would be 'QD1 for Access'.

\section{Data Collection}

Given that the population of the United Kingdom is more heavily weighted towards the English counties (Department for Business Innovation and Skills 2010) and that there are several large, metropolitan areas within North West England region, a convenience sample of the student population was taken from two universities within Greater Manchester and Merseyside. They are referred to as HEI 1 and HEI 2 where HEI is the Higher Education Institution. The sample used was a mix of first year and final year students from both universities. Two universities were used to allow for internal reliability checks between the organisations to monitor if there was any excessive bias in the sample. The mix of first and final year student sampling was to gauge if there were differences in perceptions according to how long they had been students at their respective universities.

\section{Design of CIT Questionnaire}

The CIT questionnaire was purposefully designed to elicit a hand-written account from each student of an encounter within the university context. An earlier pilot study had shown that this could take fifteen minutes to produce a rich amount of data from the majority of respondents. The learning and teaching section of the questionnaire asked for a narrative concerning formal timetabled sessions or personal encounters with teaching staff; whilst the support services section invited narratives concerning, amongst other areas, the catering service offering, the library and interactions with office administrators. The survey instrument also provided an 
opportunity for respondents to indicate whether the experience might influence loyalty behaviours in two areas, namely, (a) repurchasing intentions (intending to study at a higher level), (b) recommending the institution to others. In total, the questionnaire had space for four separate narratives (two satisfying and two dissatisfying experiences).

There were a number of prompting questions, namely (a) What occurred? (b) How did it make you feel? Appendix 1 contains the full questionnaire. Where a student had recorded a dissatisfying encounter, the questionnaire offered a prompt to record what should have happened to turn the situation into a positive experience. The questionnaire was distributed to over 350 students during taught sessions in order that the data could be captured from the majority of full time students in their first or final year of study. The dataset was then derived from the content analysis of the written anecdotal statements. The statements were concerned with individual student perceptions of their experience of university life. To address some of the concerns within the extant literature about validity and reliability, three judges were used in the content analysis and in the coding of this qualitative data.

\section{Results}

Each narrative contained between 1 to 3 identifiable determinants of quality. The list of education-specific determinants arising out of earlier research carried out by ----(2009) has been further updated to include definitions and keywords. The six new determinants of quality were identified from the narratives, namely (i) motivation, which concerned the level of motivation inspired by university personnel; (ii) praise or reward, where the student received unexpected praise for their performance, including a high mark for assessed work or a prize for outstanding work; (iii) social inclusion, was about meeting new people, usually fellow students; (iv) usefulness, 
which pertained to a number of factors, such as the subject matter stimulating the level of interest, particularly where it was something that could be applied to a work place situation. This determinant also applied to feedback on assessments; (v) value for money and finally (vi) fellow student behaviour was identified as an issue and concerned other students' behaviour impacting on the experience of an individual.

The judges discussed their individual findings and an agreement was reached for $95 \%$ of the themes. For the remaining themes a consensus was reached in terms of how to allocate one or more determinants of quality to each statement.

Of the 350 questionnaires distributed (52.1\%) from HEI 1; (47.9\%) from HEI 2 were fully or partially completed and legible, producing 915 narratives. In a similar pattern to that of Johnston (1995), more students recorded descriptions of positive experiences (483 positive narratives collected). A description of positive teaching and learning experiences was provided $(88 \%)$ of the respondents; $(67.9 \%)$ of the responses included a positive narrative relating to support services. The number of dissatisfying encounters within teaching and learning recorded was (81.5\%) and (56.3\%) reported a negative experience concerning support services. Table 1 below shows the breakdown of numbers by year of study and university of study. Where '+' is indicated this represents a positive variable; conversely ' -' represents a negative variable.

Take in Table 1. Breakdown of the number and percentage of narratives by University and by Year of Study.

Although not all narratives could be described as providing 'rich' data, it was still possible to theme even the more sparse descriptions according to the appropriate quality determinant. The cut-off point in deciding what was a critical area was at a $5 \%$ response rate in line with ----- (2008) and Johnston (1995); those achieving less that 5\% 
responses were deemed to be 'neutral' variables of quality and judged to be not so critical to students. The neutral categories were found to be tangibles; care; cleanliness, comfort; commitment; competence; courtesy; flexibility; friendliness; functionality; integrity; motivation; praise; reliability; responsiveness; security; and other student behaviour. Based on the $5 \%$ cut off point, eight variables were identified as being the primary determinants of quality within Higher Education.

\section{Satisfiers / Dissatisfiers in Higher Education}

The positive narratives described a range of experiences within the teaching and learning environment and were categorised using the HE determinants of quality. Table 2 below illustrates the frequencies of the narratives for each independent variable and the higher percentage of responses show that the critical areas for teaching and learning are: Attentiveness; Communication and Usefulness, whereas for the support servicescape the critical areas are Access; Attentiveness and Value for Money. The variables that are deemed critical have been highlighted in bold within Table 2.

Take in Table 2. Independent Variable Frequencies of Responses for Teaching, Learning and Assessment and for Support Services

\section{Critical Determinants of Quality in Higher Education}

The critical determinants of quality within Higher Education shown by these findings are:

(a) Access - This is defined as the physical approachability of service location, the level of ease of finding way around the environment, the clarity of the route, ease of contact with university staff. The keywords provided for the theming of this 
determinant of quality were convenient hours of operation / location/ sign-posting, access to services / facilities / buildings/ rooms / tutors /virtual resources. This determinant of quality was more of an issue for the support services than for teaching and learning (see Figure 1) and varied by year and university. A breakdown of HEI 1 results yielded a $40 \%$ response rate on the Access variable by final year students but only a 10\% response rate for first year students. Whilst a breakdown of HEI 2 results produced a response rate of around $15 \%$ for first year students but above $20 \%$ for final year students. Access appeared to be both a satisfier and a dissatisfier for support services, but produced less than a 5\% response for dissatisfaction within teaching and learning. 'Access' provided verbatim in the example narrative below was concerned with the student's access to library services (textbooks).

"I had taken out library books over the summer to write my dissertation, when term started again I couldn't renew them as the library system said that my student status had expired. I had to go to see my programme leader to get it sorted out which took about a week. I felt angry as the school office was telling me I had to pay late fees for books the library was telling me I couldn't return."

A total of 47 narratives expressed dissatisfaction with this variable in the support service context and also included access to computers, textbooks, and car parking facilities. A small number of the responses $(n=18)$ contained positive experiences within the teaching and learning context and 13 responses detailed dissatisfaction in the teaching and learning servicescape. The impact on loyalty intentions appear to be significant with $(\mathrm{n}=13,72 \%)$ of students confirming that the positive experience was likely to lead to them recommending their university to others. For the negative experiences, the impact was that less than half of the respondents in both universities indicated that their experience would adversely affect their recommending their university to others $(n=5,38 \%)$. 
Take in Figure 1. Access Variable by University and Year of Study (for Support Services $[\mathrm{SS}]$ and Teaching \& Learning $[\mathrm{T} \& \mathrm{~L}]$ ) as percentages.

(b) Attentiveness (helpfulness) - was defined as willingness of contact staff to provide help or giving the impression of being interested in the student; providing support. Some of the keywords used to help the judges in their content analysis were helpfulness, interested, attentive to needs, and readiness to provide service. This determinant of quality triggered a large response in both teaching and learning and support service contexts, with 81 positive narratives describing a teaching and learning experience, 34 negative narratives in the teaching and learning area, 74 positive support service narratives and 17 negative support service narratives. Figure 2 below refers.

Take in Figure 2. Attentiveness Variable by University and Year of Study (for Support Services $[\mathrm{SS}]$ and Teaching \& Learning [T\&L]) as percentages.

The majority of respondents in both universities indicated that they would recommend the university $(n=65,80 \%)$ and continue with their studies $(n=61,75 \%)$ based on their positive experiences in teaching and learning. However, only a small percentage $(\mathrm{n}=12,35 \%)$ of respondents in both universities indicated that their negative experience would adversely affect their intention to recommend the university.

Clearly, there is a level of tolerance with this quality determinant.

"Succeeding in [Named] University, as I am another EU country's student. When I arrived in the UK my language skills were not good, but with the help of lecturers I'm still studying in [named degree]."

"During this year first semester, I had an assignment to do in [named subject]. I finished my assignment but I felt there was something wrong with the structure, so I went to my lecturer and he helped (directed) in finding where the problem was and I found it in the end."

"Staff is always kind and helpful." 
"Year 1 and 2 modules taught by (name supplied) and (name supplied). Believe to be the most well thought out and structured lectures with plenty of support and supervision available. One of the 1st modules to use Blackboard e-learners website."

"I liked the way the tutors conducted their lectures with the help of hand-outs and guidance. They are always, or most of the time available for assistance."

"During exam period / coursework hand in dates, not enough resources in the form of computers / printers, queues for computers were very long - led to further panic and frustration. Worried I wouldn't be able to hand work in on time because no access to computer at home."

"Not being able to get a text book when need [sic] as other students haven't returned them. Frustrating. Should have higher fines."

(c) Availability - was defined as the amount of time that each member of a Faculty team can give to the students. It also included the availability of service goods, including the quantity and range of goods made available to students. This was not a critical determinant of quality but nevertheless warrants some discussion as there was a response rate of $6.8 \%$ in the support service environment section of the questionnaire. The narratives indicated dissatisfaction in this area. Some examples of the comments are given below. Figure 3 shows that this determinant of quality was an issue for HE1 final year students, but not the first year students.

Take in Figure 3. Availability Variable by University and Year of Study (for Support Services [SS] and Teaching \& Learning [T\&L]) as percentages.

"Parking situation. We pay $£ 156$ per year, and we are still not guaranteed a parking space. Frustrated and annoyed with uni. Stop people using it on a pay and go. Only sell enough permits for car parking spaces and only allow these people in."

"Poor computers - either system was down can't log on. Printers not working. Angry, could not get my work finished on time. Should maintain computers at a level so they can be used when needed."

"No proper food in the canteen as in halaal food. It made me feel annoyed." 
"Library- lack of resources, books. Not enough supervision on students who maybe went for a social event. Don't have long enough opening hours. It made me come in the library less and use others. Should make sure more books and computers are available to all and ensure more silent study areas and longer hours."

(d) Communication - was defined as the ability of the university to communicate with their students in a language they understand. This included clarity, completeness, and accuracy, both the verbal and written form, and the ability of university employees to listen to and understand the student. It included explaining the service itself, the costs involved, the trade-offs between service and cost, assuring the student that a problem will be handled. The keywords provided to judges to aid in their decision-making were teaching methods, feedback on module / subject, cancelled classes, work placement supervision, and module organisation. This variable produced a large response from students, with 80 narratives including a description of a satisfying encounter in the area of teaching and learning, and 135 narratives describing a dissatisfactory teaching and learning encounter. The larger response came from HEI 2 with 58 students recording a positive teaching and learning incident, as opposed to just 22 from HEI 1. Adverse comments from each university were similar (63 HEI 1: 72 HEI 2). Figure 4 below refers.

Take in Figure 4. Communication Variable by University and Year of Study (for Support Services [SS] and Teaching \& Learning [T\&L]) as percentages.

There were far less narratives concerned $(n=3, .01 \%$ positive experiences; $n=6, .03 \%$ for negative experiences) with support services in terms of communication. Some examples of communication-themed narratives are provided below:

"Teacher making jokes but in an appropriate time and keep on teaching seriously."

"Use of very simplistic terms within an otherwise complicated subject in putting cases into everyday terms and in injecting enthusiasm." 
"Not just reading, but involved different activities to help to learn and focus more such as videos, group work."

"Going through worked examples of past exam questions as a group”.

"The topic was boring, too easy, lecturer was in a bad mood and stressed. Felt disappointed. The lecturer should have explained why she was moody or apologised for being stressed."

'I had bought a book for the class which wasn't on the current year's reading list but was on a previous one. The tutor wasn't happy that I had bought this book as he was using it to photocopy lecture notes and give us the exercises to complete. I felt upset as the book was relevant to the course and I had spent money on it. The tutor could have explained that he was using that book to plan classes out of and I would have just used it for private study and not bought it to class."

(e) Social Inclusion - was defined as meeting new friends and feeling a sense of belonging. This was identified by the students as a satisfier with a number of responses concerned with the social aspect of university life. There were 10 positive narratives in the area of teaching and learning and 23 in the support services area. Examples of social inclusion are provided below:

"Meeting colleagues outside uni."

"Freshers Week."

"On the first week all people I encountered were very friendly. I felt more relaxed and helped me settle in better."

"Too many introduction lectures in the first week. I felt distanced. Couldn't go out and make new friends as much."

(f) Usefulness - was defined as the subject matter stimulated the level of interest from the student, the topic can be applied in the work-place, or in real life situations; industry-based learning, computer programmes. It was also applied to feedback received on assignment submissions and informed feedback on examinations. Although the definition did not include how this would apply to the support services environment, one respondent referred to usefulness in his narrative. This is provided below. The keywords provided for judging were added-value, learning, meaningful 
and add to skills. Usefulness appears to be largely a satisfier with 41 descriptions

concerning a positive teaching and learning experience that was useful to the student.

"When I received a piece of coursework back, I was given good feedback which enabled me to improve in the future. It made me feel good as I knew what I needed to do to improve my mark."

"Learning to use a wide range of computer programs, especially excel for accounting purposes. Felt competent using unfamiliar computer programs."

"Using Blackboard for help and guidance in modules."

"The 'jobs worth' security staff who work in the library and don't seem to do anything useful. Either sack them or get rid of the card swipe gates and make guards do something for their money."

(g) Value for money - was defined as the fees paid for a programme of study,

library fines, and printing costs. It also included goods sold as part of the service, for example, cafeteria / bistro products. Keywords were Expensive, value, price, cost.

The concept of feeling they had received value for their money was mainly in the area of support services, with 34 negative responses received for this area.

"Paying stupid amounts of money for education. There should be more help from the uni with finance."

"I got a big library fine. They could have let me off with the fine."

"Food services (lack of decent, cheap food)."

"Paying for printing - disappointing."

"The food prices are lot more expensive in the Students Union than in town."

(h) Achievement - was defined as when the student feels a sense of achievement, usually regarding something they have learned, for example, encountering a new software package, or developing presentation skills. A sense of achievement was referred to in a positive light in 27 teaching and learning narratives.

"In (subject named) tutorials were very involving and very helpful towards passing the course. I felt confident in that subject." 
"For our [name supplied] module we had to deliver a $30 \mathrm{~min}$ presentation. This helped us to gain skills which will be useful later in life. I felt I had really achieved something as I had never spoken in front of people while presenting slides."

In summary, a number of rich narratives covering a wide range of determinants of quality in Higher Education were collated and analysed. Figure 5 below shows each determinant of quality in terms of the number of responses that were themed according to the variable in question.

Take in Figure 5.

Every determinant is represented in the students' feedback, but Communication and Attentiveness where the variables that resulted in the most response (Communication $=224$ narratives; Attentiveness $=206$ narratives). Figure 6 shows the determinants of quality for Higher Education in order of frequency.

Take in Figure 6. Determinants of Service Quality in Higher Education for Business School Students in order and count of frequency.

\section{Discussion and Recommendations}

The main aim of this research was to test the validity of the conceptual model of student satisfaction with their university experience developed by Douglas et al (2008). This aim has been achieved by utilising the qualitative research method known as Critical Incident Technique on a larger scale, involving more student respondents over two universities, rather than one. This study has shown that the critical areas of quality, i.e. those that will both satisfy students and dissatisfy students were as follows:

\section{Teaching and Learning Quality Determinants:}

- Access;

- Attentiveness; 
- Communication;

- Availability was critical only for Final Year students in both universities and for First Year students only in one university (HEI 1).

Within an earlier study Douglas et al (2008) Communication was also a critical area for students in the context of teaching, learning and assessment. Therefore the findings here validate earlier findings with regards to Communication.

\section{Support Services Quality Determinants:}

- Access;

- Attentiveness (Final Year only). It was a Satisfier, but not a Dissatisfier for First Year students).

- Availability;

- Communication (First Year students only for both institutions; Final Year students only for HEI 2). It was a dissatisfier but not a satisfier for Final Year students of HEI 1.

Within the earlier study by Douglas et al (2008) Access was also a critical area. The Responsiveness variable resulted in a relatively small number of responses from this study with less than $2 \%$ in each context. This differs from the earlier findings of Douglas et al (2008) who proposed that this was a critical area for their study University. It is not clear why this should vary, although that study was smaller than this current study and involved only one institution. The neutral variables in this study were Tangibles, Care, Cleanliness, Comfort, Commitment, Competence, Courtesy, Flexibility, Friendliness, Functionality, Integrity, Motivation, Praise, Reliability, Responsiveness, Security, and Fellow Student Behaviour (refer to Table 2 for the percentage scores); thus agreeing to a large extent with the findings of previous studies. 
The area that created the most dissatisfaction in this study was Communication. However, its impact on the students' loyalty intentions was relatively small, with only $28 \%$ for HE 1 and $26 \%$ for HEI 2 indicating that they would be adversely influenced in their recommendation of the university. It is nevertheless clearly an area that both universities should focus their attentions on. Moreover, in order to reach the standard of flawless performance, it is recommended that an analysis by Higher Education Institutions of their satisfiers would assist in identifying how the service gets it right for their primary customers.

A number of responses provided a suggestion about what should have happened to make their experience a more positive one. In the area of teaching and learning this was $75 \%$ of responses and for support services this was $52 \%$ of responses. This will be the subject of future work as it included some useful suggestions that could be used for training purposes and for the setting of standards of service.

There was some overlap between some of the determinants of quality, for instance, social inclusion and friendliness. However, most of the narratives make interesting reading and do indeed contain rich data that is a lot more meaningful than mean scores for perceptions or attitudes, which on their own tell an individual staff member very little about their professional practice and how they might improve. This could be a much more effective mechanism for measuring and improving service quality in an educational setting.

It is recognised that this article has focused on one type of student to gather perspectives of university life, that is, the business undergraduate. It would be interesting to also seek the views of a broader sample of undergraduate and postgraduate students as well as other stakeholders to assess whether communication, 
access and attentiveness are critical to quality for them. This research could also be extended to students of other disciplines outwith the business subject area.

The implications for universities and their staffing groups are that the above critical areas are where the focus needs to be made, as they are both satisfiers and dissatisfiers, which will impact on loyalty behaviours, including word of mouth. Word of mouth will strongly influence final year students in what they say via the National Student Survey which can adversely impact league table positions. 
Table 1: Breakdown of the number and percentage of narratives by University and year of study.

\begin{tabular}{|c|c|c|c|c|c|}
\hline & & $\begin{array}{l}\text { Teaching } \\
\text { and } \\
\text { Learning } \\
(+) \\
(n=273)\end{array}$ & $\begin{array}{l}\text { Teaching } \\
\text { and } \\
\text { Learning } \\
(-) \\
(n=252)\end{array}$ & $\begin{array}{l}\text { Support } \\
\text { Services } \\
(+) \\
(n=213)\end{array}$ & $\begin{array}{l}\text { Support } \\
\text { Services (-) } \\
(\mathbf{n}=177)\end{array}$ \\
\hline & \multicolumn{5}{|c|}{ Number plus $\%$ of the total number of respondents (i.e. out of 309) } \\
\hline \multirow[t]{3}{*}{ HEI 1} & First Year & $48(5.2 \%)$ & $38(4.1 \%)$ & $35(3.8 \%)$ & $20(2.1 \%)$ \\
\hline & Final Year & $91(9.9 \%)$ & $100(10.9 \%)$ & $76(8.3 \%)$ & $63(6.8 \%)$ \\
\hline & Total & 139 & 138 & 111 & 83 \\
\hline \multicolumn{6}{|l|}{ HEI 2} \\
\hline & First Year & $73(7.9 \%)$ & $62(6.7 \%)$ & $59(6.4 \%)$ & $48(5.2 \%)$ \\
\hline & Final Year & $61(6.6 \%)$ & $52(5.6 \%)$ & $40(4.3 \%)$ & $43(4.7 \%)$ \\
\hline & Total & 134 & 114 & 99 & 91 \\
\hline
\end{tabular}

Table 2: Independent Variable Frequencies of Responses for Teaching, Learning and Assessment and for Support Services

\begin{tabular}{|l|l|l|l|l|}
\hline Variables & $\begin{array}{l}\text { TLA } \\
\text { Satisfiers }\end{array}$ & $\begin{array}{l}\text { TLA } \\
\text { Dissatisfiers }\end{array}$ & $\begin{array}{l}\text { SS } \\
\text { Satisfiers }\end{array}$ & $\begin{array}{l}\text { SS } \\
\text { Dissatisfiers }\end{array}$ \\
\hline Access & $\mathbf{5 . 8 \%}$ & $4.2 \%$ & $\mathbf{1 5 . 5 \%}$ & $\mathbf{1 5 . 2 \%}$ \\
\hline Tangibles & Nil & Nil & $0.3 \%$ & $0.6 \%$ \\
\hline Attentiveness & $\mathbf{2 6 . 2 \%}$ & $\mathbf{1 1 \%}$ & $\mathbf{2 3 . 9 \%}$ & $\mathbf{5 . 5 \%}$ \\
\hline Availability & $1.3 \%$ & $3.9 \%$ & $3.6 \%$ & $\mathbf{6 . 8 \%}$ \\
\hline Care & $0.3 \%$ & $0.3 \%$ & $1 \%$ & $0.3 \%$ \\
\hline Cleanliness & $0.3 \%$ & Nil & $1 \%$ & $0.6 \%$ \\
\hline Comfort & $0.3 \%$ & $0.6 \%$ & Nil & Nil \\
\hline Commitment & $0.3 \%$ & Nil & $0.3 \%$ & Nil \\
\hline Communication & $\mathbf{2 5 . 9 \%}$ & $\mathbf{4 3 . 7 \%}$ & $1 \%$ & $1.9 \%$ \\
\hline Competence & $1 \%$ & $1.3 \%$ & $1.6 \%$ & $3.6 \%$ \\
\hline Courtesy & $0.3 \%$ & $0.6 \%$ & Nil & Nil \\
\hline Flexibility & $0.6 \%$ & $1.9 \%$ & $0.3 \%$ & $1.3 \%$ \\
\hline Friendliness & $2.3 \%$ & $0.6 \%$ & $2.3 \%$ & $1.6 \%$ \\
\hline Functionality & $2.6 \%$ & $0.3 \%$ & $3.6 \%$ & $4.2 \%$ \\
\hline Integrity & $0.6 \%$ & Nil & Nil & $0.3 \%$ \\
\hline Motivation & $2.3 \%$ & $1.3 \%$ & $0.6 \%$ & Nil \\
\hline Praise & $2.6 \%$ & Nil & $0.6 \%$ & $0.6 \%$ \\
\hline Reliability & $0.6 \%$ & $2.3 \%$ & Nil & $0.6 \%$ \\
\hline Responsiveness & $0.3 \%$ & $1.3 \%$ & $0.6 \%$ & $0.3 \%$ \\
\hline Security & $0.3 \%$ & Nil & $0.3 \%$ & Nil \\
\hline Social Inclusion & $3.2 \%$ & Nil & $\mathbf{7 . 4 \%}$ & $1.9 \%$ \\
\hline Usefulness & $\mathbf{1 3 . 3 \%}$ & $2.3 \%$ & $2.9 \%$ & $0.3 \%$ \\
\hline $\begin{array}{l}\text { Value for } \\
\text { Money }\end{array}$ & $0.3 \%$ & $1 \%$ & $1 \%$ & $\mathbf{1 1 \%}$ \\
\hline Achievement & $\mathbf{8 . 7 \%}$ & $1.9 \%$ & $0.3 \%$ & $0.3 \%$ \\
\hline Other Students & $0.3 \%$ & $2.3 \%$ & $0.3 \%$ & $0.3 \%$ \\
\hline & & & & \\
\hline
\end{tabular}




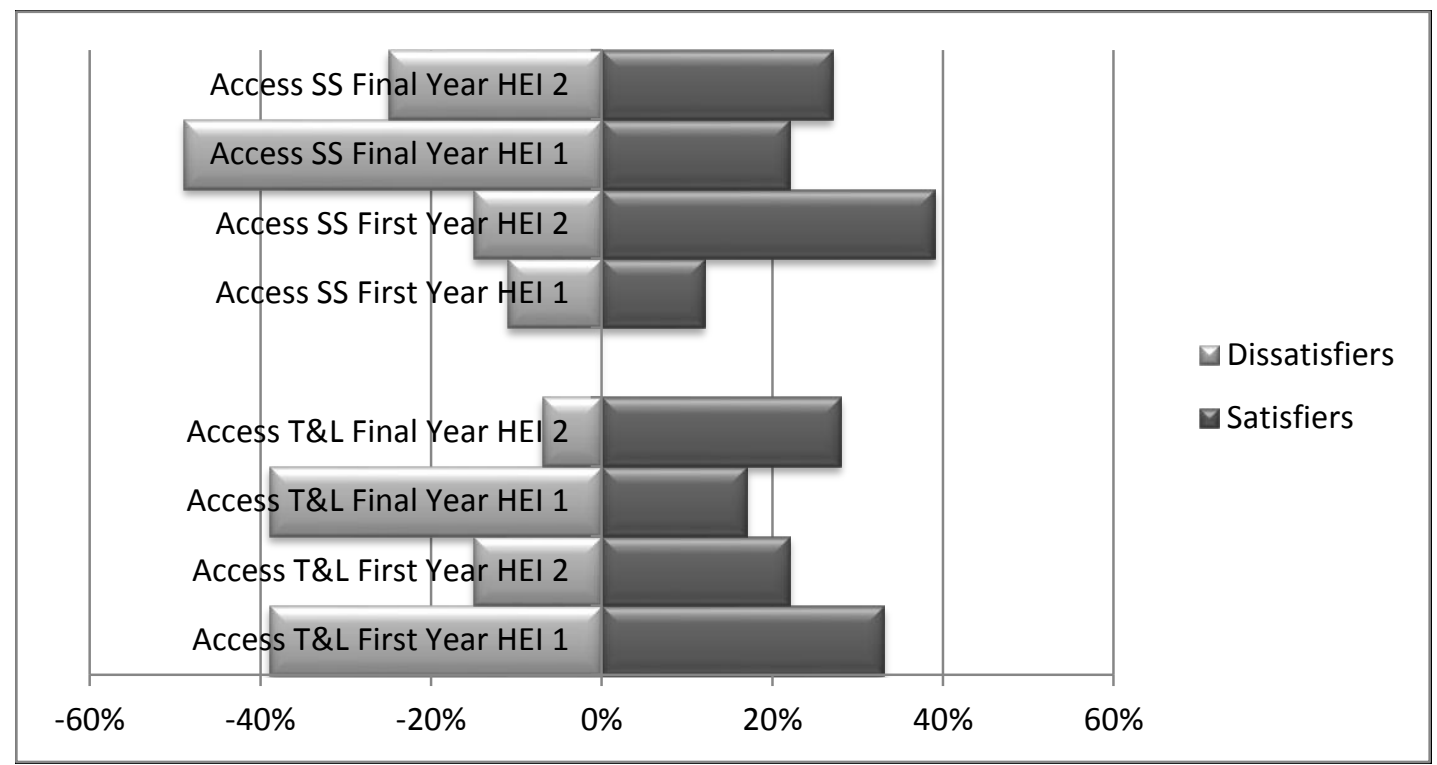

Figure 1: Access Variable by University and Year of Study (for Support Services [SS] and Teaching \& Learning [T\&L]) as percentages.

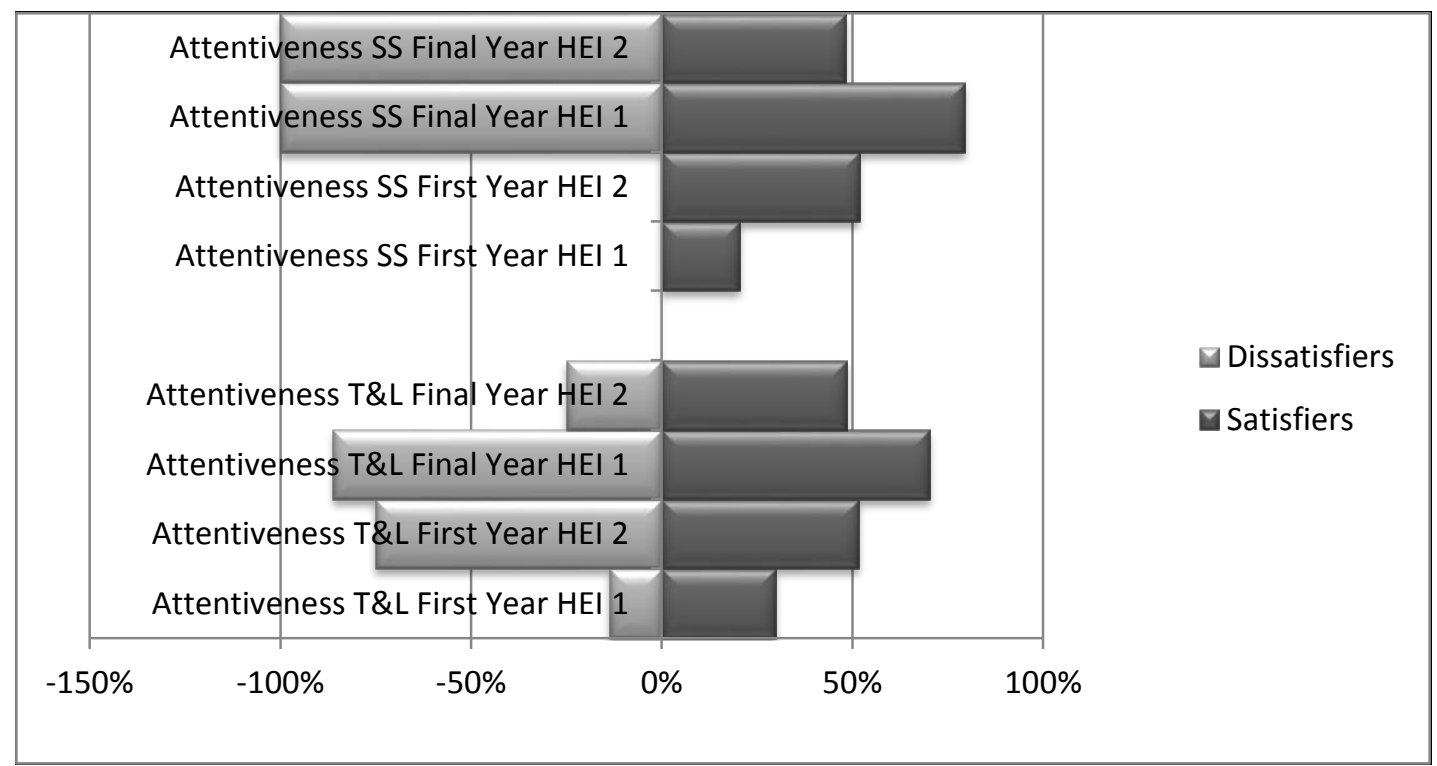

Figure 2: Attentiveness Variable by University and Year of Study (for Support Services [SS] and Teaching \& Learning $[\mathrm{T} \& \mathrm{~L}]$ ) as percentages 


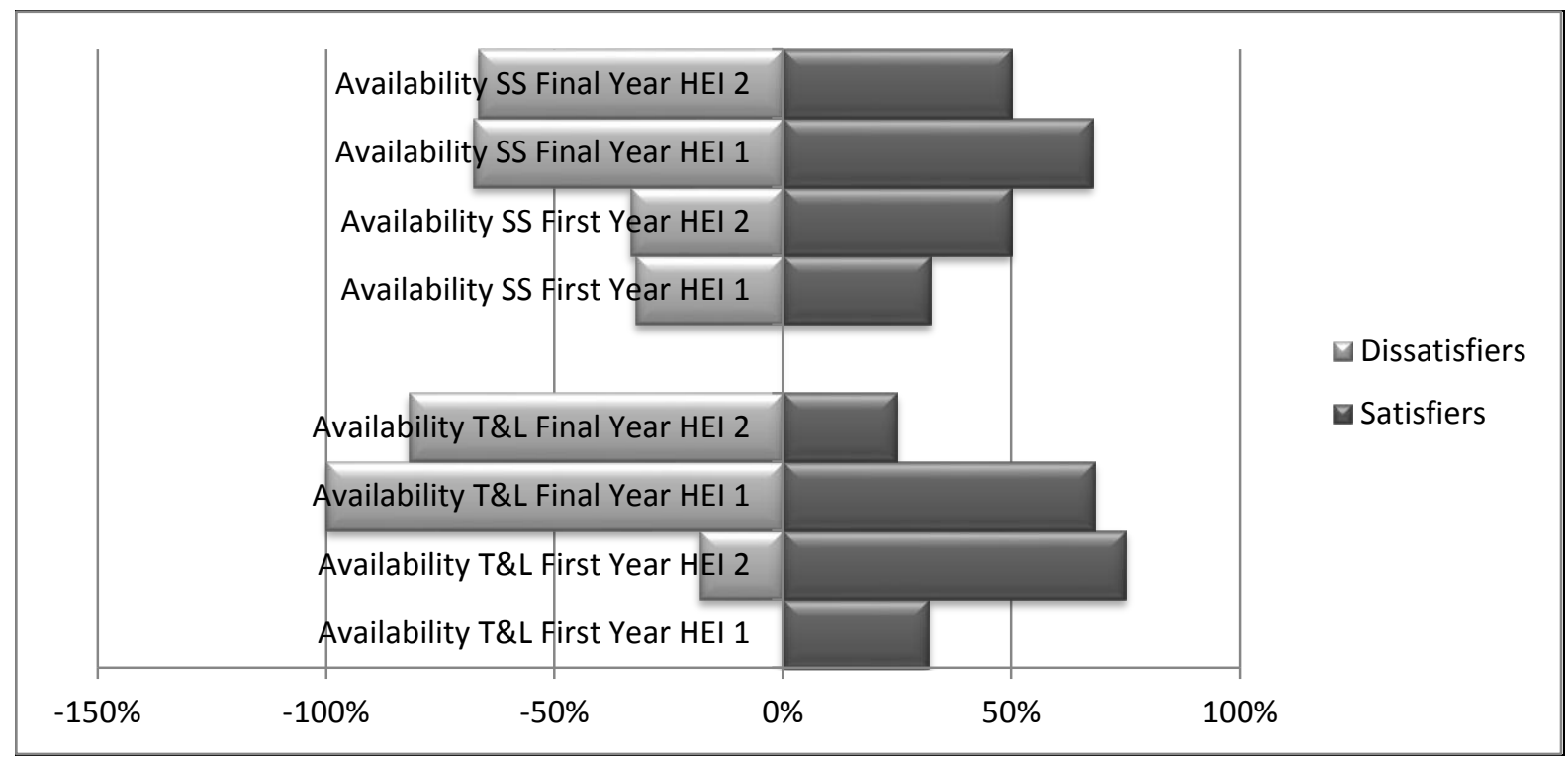

Figure 3: Availability Variable by University and Year of Study (for Support Services [SS] and Teaching \& Learning [T\&L]) as percentages.

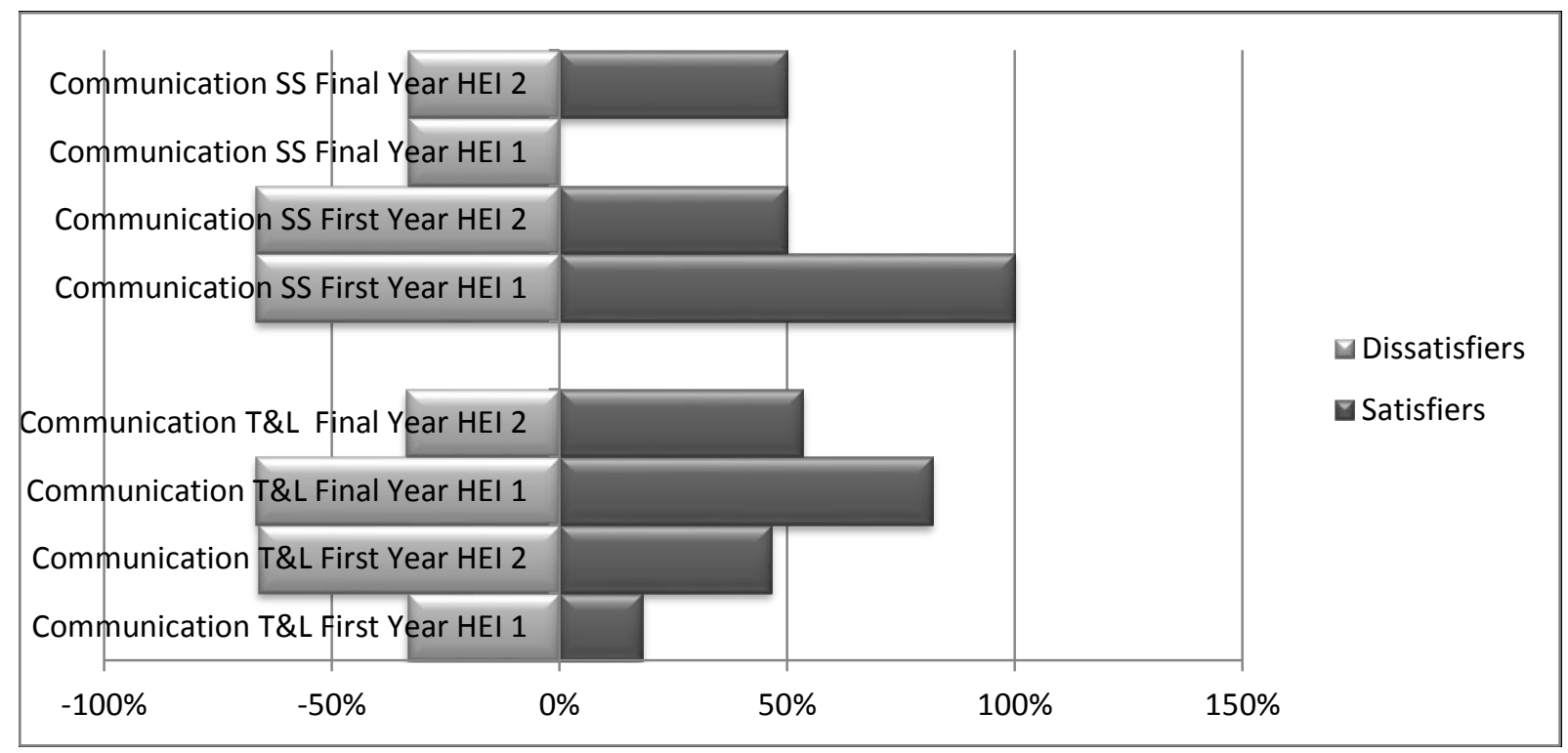

Figure 4: Communication Variable by University and Year of Study (for Support Services $[\mathrm{SS}]$ and Teaching \& Learning $[\mathrm{T} \& \mathrm{~L}]$ ) as percentages. 


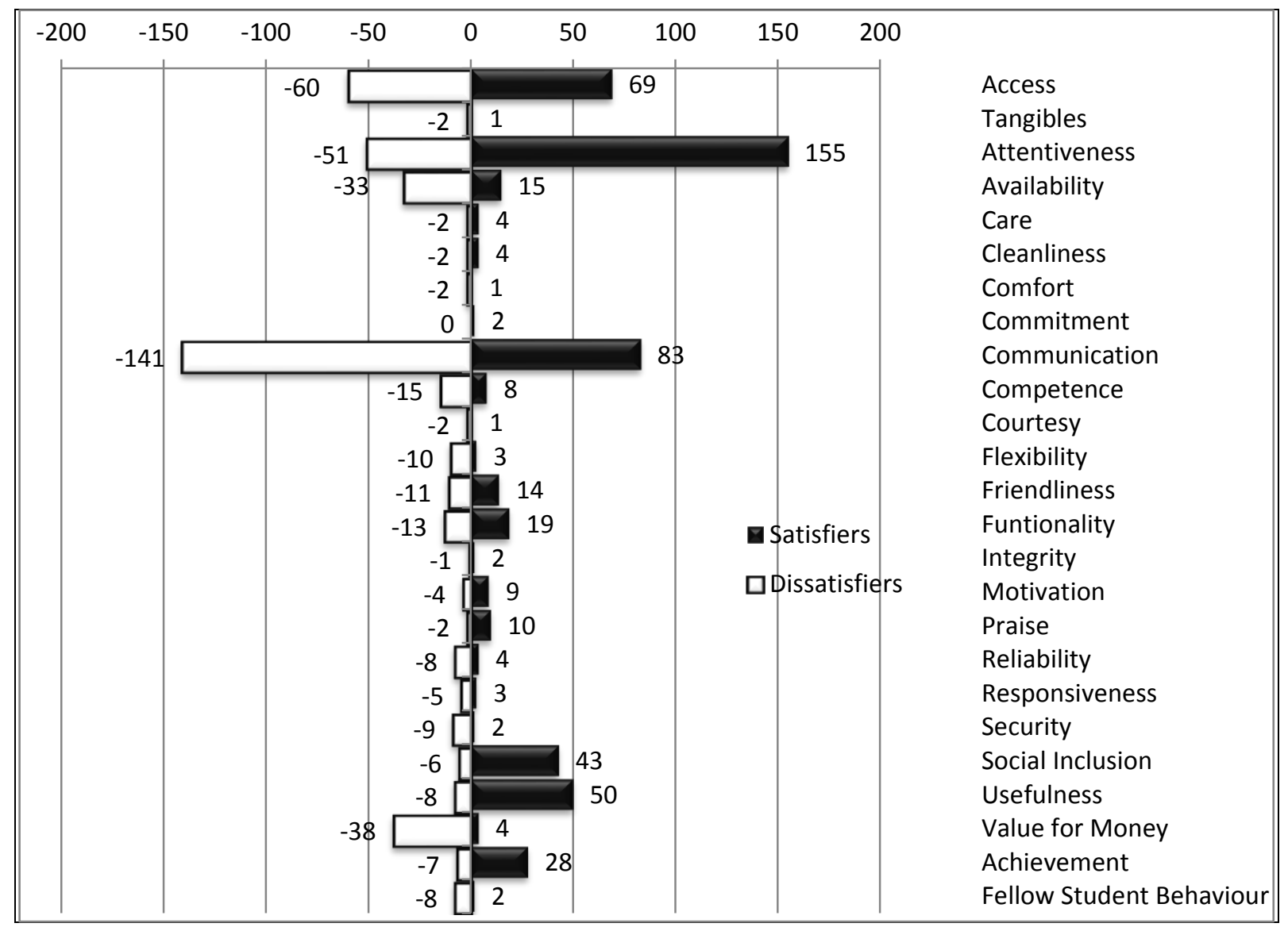

Figure 5: Counts of the sources of student satisfaction and dissatisfaction in Higher Education

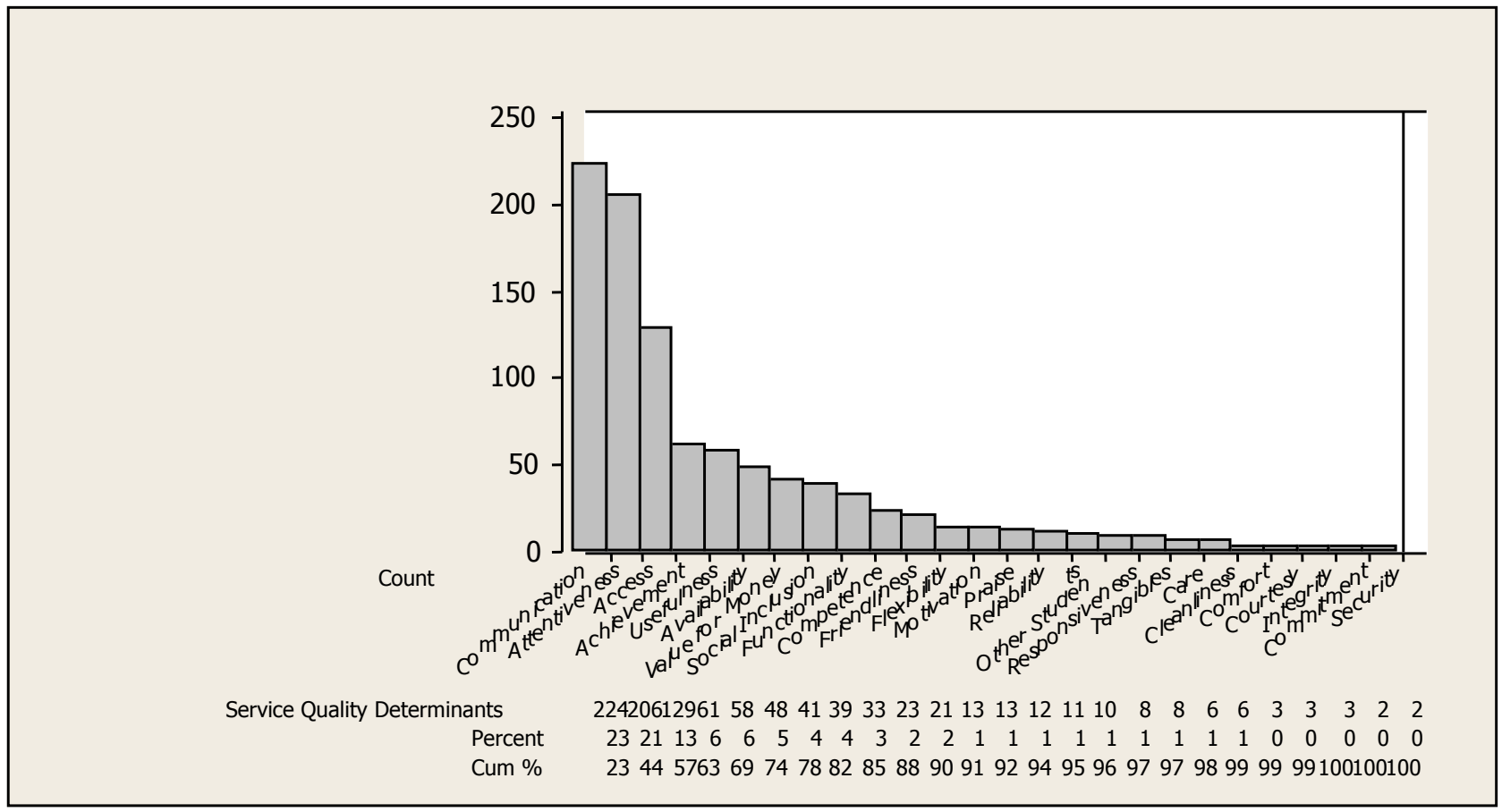

Figure 6. Service Quality Determinants in Higher Education for Business School Students in order and count of frequency. 


\section{References}

Athiyaman, A. (1997) Linking student satisfaction and service quality perceptions: the case of university education, European Journal of Marketing, 31, No. 7:. 528540.

Baker, M. (2010) US students start to question degree costs, $18^{\text {th }}$ September 2010 available at http://www.bbc.co.uk/news/education-11344228 (accessed on 16th March 2012).

Biolos, J. (2002) Six Sigma Meets the Service Economy, Harvard Management Update, A Newsletter from Harvard Business School publishing

Bitner, M.J., Booms, B.H. and Stanfield Trenault, M. (1990) The Service Encounter: Diagnosing Favourable and Unfavourable Incidents, Journal of Marketing, 54, January: 71-84.

Bitner, M.J., Booms, B.H. and Mohr, L.A. (1994) Critical Service Encounters: The Employee's Viewpoint, Journal of Marketing, 58 (October): 95-106.

British Broadcasting Company (2012) University tuition fees list available at http://www.bbc.co.uk/news/education-12880840 accessed on 20th February 2012.

Brūggen, E.C., Foubert, B. and Gremler, D.D. (2011) Extreme Makeover: Short and Long-Term Effects of a Remodeled Landscape, Journal of Marketing, 75, 5: 7187.

Campbell, D. T. and Fiske, D. W. (1959) Convergent and discriminant validity by the multi-trait multi-method matrix, Psychological Bulletin, vol. 56, 81-105

Carlzon, J. (1987) Moments of Truth: New Strategies for Today's Customer-Driven Economy, Ballinger Publishing Company.

Carlzon, J (2006) What business leaders can learn from the moment of truth: an interview with former SAS CEO Jan Calzon, available at www.customerthink.com accessed on $7^{\text {th }}$ March 2012.

Charmaz, K. (2006) Constructing Grounded Theory in the $21^{\text {st }}$ Century: A Practical Guide Through Qualitative Analysis, London, Sage Publications.

Cherryholmes, C. H., 1992. Pragmatism and Scientific Realism. Educational Researcher, 21(6), pp. 13-17.

Creswell, J. W., 2009. Research Design: Qualitative, Quantitative and Mixed Methods Approach. 3rd ed. California: Sage.

Danermark, B. Ekstrom, M. Jakobsen, L and Karlsson J. Ch. 2002. Explaining Society: Critical Realism in the Social Sciences, London, Routledge

Dean, A.A. (2011) "Improving the educational experience of HLST students in Higher Education", The Higher Education Academy: Hospitality, Leisure, Sport and Tourism Network.

Denzin, N. 1989. The Research Act, Englewood Cliffs, NJ, Prentice Hall

Department for Business Innovation and Skills. "DfE: Education and Training Statistics for the United Kingdom 2010, 14th Edition of Education and Training Statistics." Department for Education. 2010.

http://www.education.gov.uk/rsgateway/DB/VOL/v000992/index.shtml (accessed November 30, 2011).

Department for Business, Innovation and Skills (2011) Higher Education White Paper: Students at the Heart of the System. Department for Business Information and Skills, $28^{\text {th }}$ June 2011.

DeShields Jr., O.W., Kara, A. and Kaynak, E. (2005) Determinants of business student satisfaction and retention in higher education: applying Herzberg's two- 
factor theory, International Journal of Educational Management,19, No.2:128139

Douglas, J., McClelland, R. and Davies, J. (2008) The development of a conceptual model of student satisfaction with their experience in higher education. Quality Assurance in Education XVI, no. 1: 19-35.

Douglas, J.A., McClelland, R., Davies, J. and Sudbury, L. (2009) Using critical incident technique to capture the voice of the student, The TQM Journal, 21, No.4: 305-318.

Downward, P. M. and Mearman, A. (2004) Presenting 'demi-regularities' of pricing behavior: the need for triangulation, in Forstater, M. and Wray, L. R. (eds), Contemporary Post Keynesian Analysis: A Compendium of Contributions to the Seventh International Post Keynesian Workshop, New York, Elgar

Downward, P. and Mearman, A. (2006) Retroduction as mixed-methods triangulation in economic research: reorienting economics into social science Cambridge Journal of Economics pp.1-23

Eckel, P.D. (2008) Mission Diversity and the Tension between Prestige and Effectiveness: An Overview of US Higher Education, Higher Education Policy, 21: 175-192.

Eckel, P.D. and King, J. E. (2004) An overview of higher education in the United States: Diversity, Access and the Role of the Marketplace, Washington DC: American Council on Education.

Edvardsson, B. and Roos, I. (2001) Critical incident techniques: Towards a framework for analysing the criticality of critical incidents, International Journal of Service Industry Management, 12, No.3: 251-268

Edvardsson, B and Strandvik, T (2000) Is a critical incident critical for a customer relationship? Managing Service Quality, 10, No.2: 82-91

Fitzsimmons, J.A. and Fitzsimmons, M. J. (2004) Service Management: Operations, Strategy and Information Technology, $4^{\text {th }}$ Edition, New York, McGraw Hill.

Flanagan, J.C. (1954) The Critical Incident Technique, Psychological Bulletin, 51, No.4: 327-358.

Gremler, Dwayne D. (2004) The Critical Incident Technique in Service Research." Journal of Service Research VII, no. 1: 65-89.

Guba, E. and Lincoln, Y., 1994. Competing Paradigms in Qualitative Research. In Denzin, N.K. and Lincoln, S. (Eds.) Handbook of Qualitative Research (pp 105 - 117) Thousand Oaks, CA: Sage

Herzberg, F., Mausner, B. and Snyderman, B.B. (1967) The Motivation to Work, $2^{\text {nd }}$ Ed., Wiley, New York, NY.

Higher Education Funding Council for England (2012) The Higher Education Funding Council for England available at http://www.hefce.ac.uk/ accessed on $5^{\text {th }}$ March 2012.

Huda, S. and Akhtar, A. Critical Service Encounters: The Employee's Viewpoint (A Study on Restaurant Services in Dhaka City), Global Journal of Management and Business Research, 10, 1.

Jick, T. D. 1979. Mixing qualitative and quantitative methods: triangulation in Action. In Van Manen, J. (ed.), Qualitative Methodology, London, Sage Manen, J. (ed.), Qualitative Methodology, London, Sage

Johnson, B. and Christensen, L. (2004) Educational Research: Quantitative, Qualitative, and Mixed Approaches, $2^{\text {nd }}$ Edition, Boston, Pearson, Allyn and Bacon. 
Johnston, R (1995) "The determinants of service quality: satisfiers and dissatisfiers", International Journal of Service Industry Management. 6, No.5: 53-71

Kemppainen, J.K. (2000) The critical incident technique and nursing care quality research, Journal of Advanced Nursing, 32, No.5: 1264-1271.

LeBlanc, G. and Nguyen, N. (1997) Listening to the Customer's Voice: Examining Percieved Service Value among Business College Students, International Journal of Educational Management, 13, no. 4: 187-198.

Liamputtong, P. (2009) Qualitative Research Methods, $3^{\text {rd }}$ Edition, Oxford University Press.

Lizuka, Y. (2012) Is quality still alive in Japan? Quality World, 38, No. 2: 24-29.

Lockshin, L and McDougall, G. (1998), Service problems and recovery strategies: an examination of the critical incident technique in a business-to-business market, International Journal of Retail and Distribution Management, 26, No.11: 429438

Nair, C.S. Murdocj, N. and Mertova, P. (2011) Benchmarking the student experience: the offshore campus experience, The TQM Journal, XXIII, no.6: 585-597.

National Student Survey http://www.thestudentsurvey.com/ accessed on $18^{\text {th }}$ January 2012

Parasuraman, A., Zeithaml, V.A. and Berry, L.L. (1985) A Conceptual Model of Service Quality and Its Implications for Future Research, The Journal of Marketing, 49, No. 4 (Autumn, 1985): 41-50

Saunders, M. And Lewis, P. (2012) Doing Research in Business and Management: An Essential Guide to Planning Your Project, England, Prentice Hall, Pearson Education.

Saunders, M., Lewis, P. and Thornhill, A. (2009) Research Methods for Business Students, $5^{\text {th }}$ Edition, Prentice Hall, England, Pearson Education.

Shih, Fu-Jin 1998. Triangulation in nursing research: issues of conceptual clarity and purpose, Journal of Advanced Nursing, vol. 28, 631-41

Webb, E. J., Campbell, D. T., Schwartz, R. D. and Sechrest, L. (1966) Unobtrusive Measure: Nonreactive Measures in the Social Sciences, Chicago, Rand McNally

Zineldin, M., Camgoz Akdag, H. and Vasicheva, V. (2011) Assessing Quality in Higher Education: new criteria for evaluating students' satisfaction, Quality in Higher Education, 17, No.2: 231-243. 
Appendix 1

\section{STUDENT EXPERIENCE QUESTIONNAIRE}

SECTION 1: ABOUT YOU (PLEASE TICK THE RELEVANT CIRCLE)

OMale

UK Student

OFemale

$\bigcirc$ International EU Student

International Non-EU Student 
1. Please describe a positive Teaching, Learning and Assessment Experience that you have at this university.

(a) What occurred?

(b) How did it make you feel?

(c) Would this positive experience influence any of the following:

(i) You recommending the University

(ii) You enrolling for further study at this University

(iii) You staying on the course.

2. Please describe a negative Teaching, Learning and Assessment Experience that you have at this university.

(a) What occurred?

(b) How did it make you feel?

(c) Would this positive experience influence any of the following:

(i) You recommending the University

(ii) You enrolling for further study at this University

(iii) You staying on the course.

(d) What could have happened to improve the situation? 


\section{SECTION 3: SUPPORT SERVICES EXPERIENCES}

3. Please describe a positive Support Services Experience that you have at this university.

(a) What occurred?

(b) How did it make you feel?

(c) Would this positive experience influence any of the following:

(iv) You recommending the University

(v) You enrolling for further study at this University

(vi) You staying on the course.

4. Please describe a negative Support Services Experience that you have at this university.

(a) What occurred?

(b)

How did it make you feel?

(c) Would this positive experience influence any of the following:

(iv) You recommending the University

(v) You enrolling for further study at this University

(vi) You staying on the course.

(d) What could have happened to improve the situation?

Total Number of Words $=9004$ 